\title{
Correction to: Expression of glucose transporters in the human amnion derived mesenchymal stromal cells under normoglycemic and hyperglycemic conditions
}

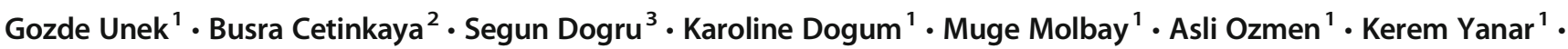 \\ Dijle Kipmen-Korgun $^{3} \cdot$ Sadi Koksoy ${ }^{4} \cdot$ Mehmet Sakinci $^{5} \cdot$ Emin Turkay Korgun $^{1}$
}

Published online: 5 February 2021

(C) Institute of Molecular Biology, Slovak Academy of Sciences 2021

Correction to: Biologia (2020) 75:299-308

https://doi.org/10.2478/s11756-019-00350-8

The original article was published with errors found in Fig. 3. The following is the intended and correct rendering of Fig. 3

Publisher's note Springer Nature remains neutral with regard to jurisdicwith caption:

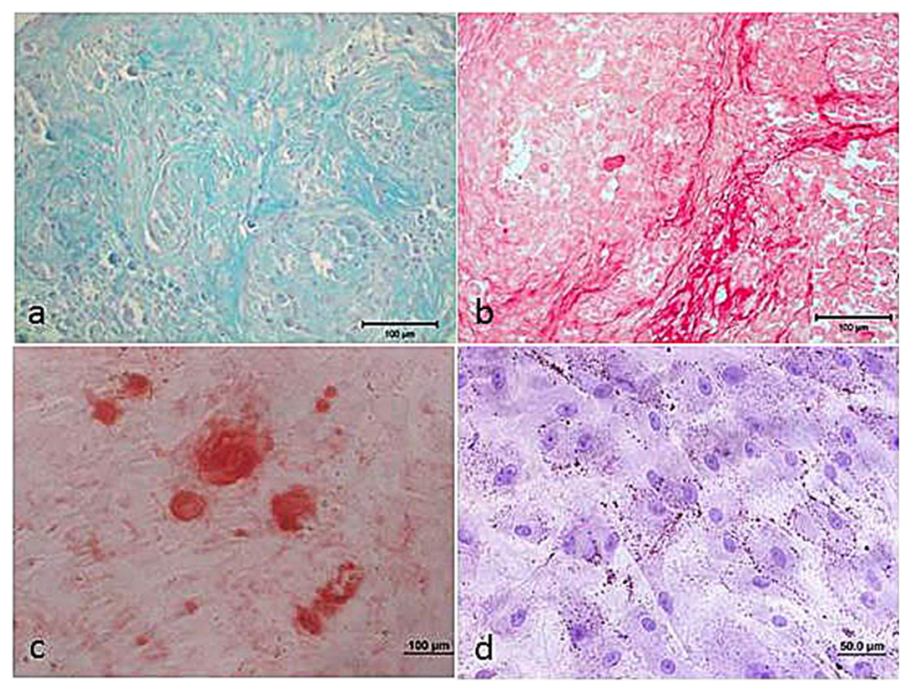

Fig. 3 Stainings of a Alcian Blue and $\mathbf{b}$ Sirius Red for chondrogenic differentiation, $\mathbf{c}$ Alizarin Red S for osteogenic differentiation, d Oil red O for adipogenic differentiation

The online version of the original article can be found at https://doi.org/ $10.2478 / \mathrm{s} 11756-019-00350-8$

Emin Turkay Korgun

korgun@akdeniz.edu.tr

1 Department of Histology and Embryology, Medical Faculty, Akdeniz University, Antalya, Turkey

2 Department of Histology and Embryology, Medical Faculty, Bulent Ecevit University, Zonguldak, Turkey
Department of Biochemistry, Medical Faculty, Akdeniz University, Antalya, Turkey

4 Department of Medical Microbiology and Immunology, Medical Faculty, Akdeniz University, Antalya, Turkey

5 Department of Obstetrics and Gynecology, Medical Faculty, Akdeniz University, Antalya, Turkey 